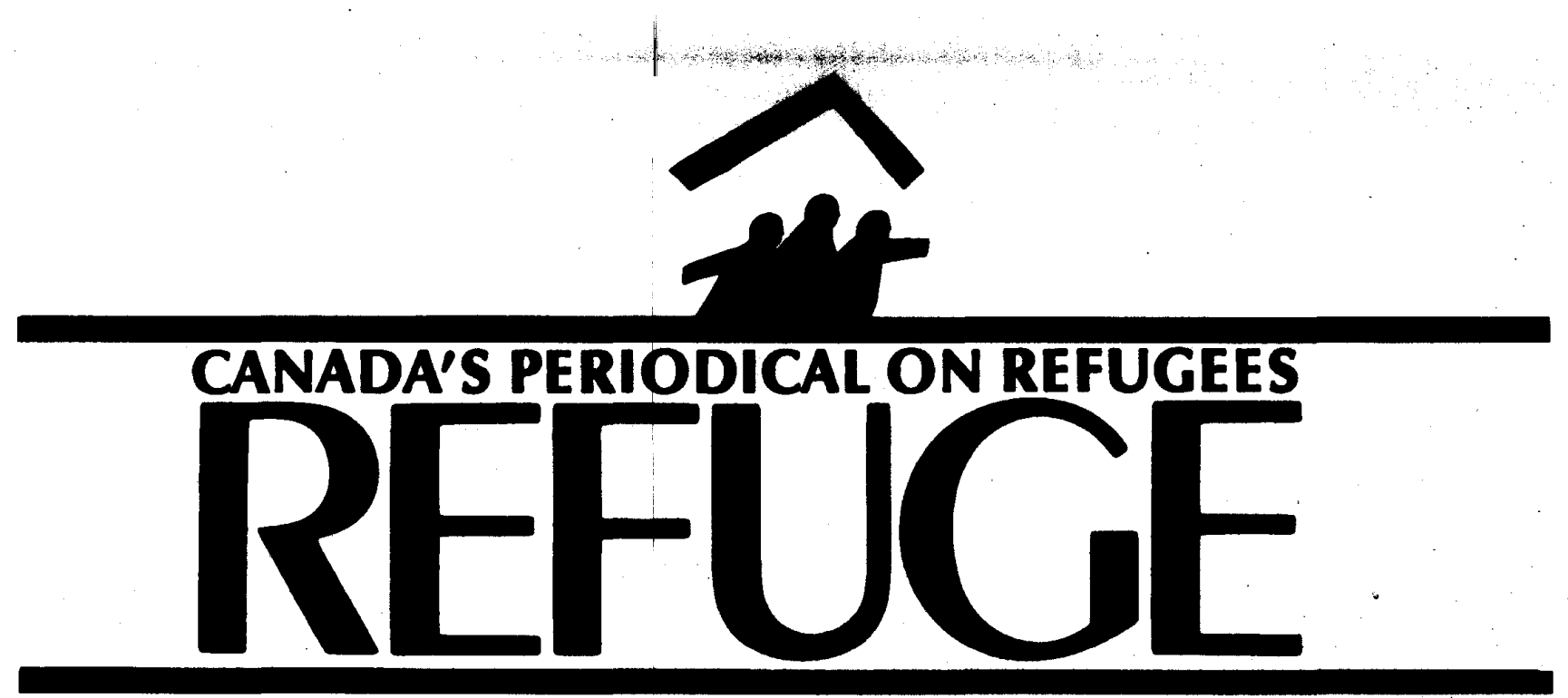

Vol. $17 \bullet$ No. 1

February 1998

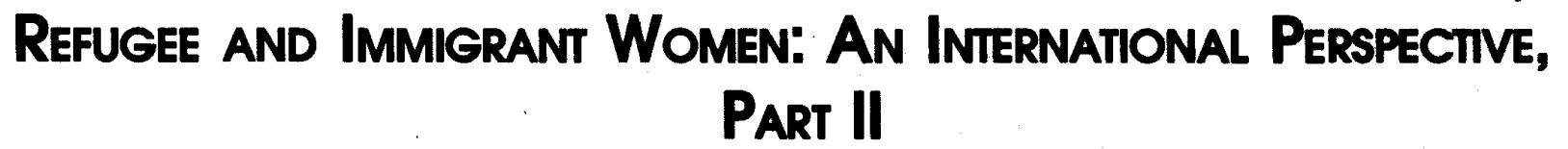

\title{
Introduction: Refugee and Immigrant Women as Workers
}

\section{Guida Man}

Women all over the world havealways worked. From sunrise to sunset, women arealways busy working. They are often engaged in the formal labour market, working in factories, hospitals, schools, businesses; and in the informal labour market, doing home sewing, babysitting, or bartering; as well as being occupied in household work, cooking for others, feeding theirbabies, washing clothes, fetching water, cleaning house, caring for the aged and the infirmed, listening to other people's problems. The work that women do are important and indispensable as part of the household strategy for survival, and yet they are often invisible and taken for granted because women are not being recognized as legitimate workers.

This issue of Refuge assembles a collection of studies which represent the voices of refugee and immigrant women. In particular, these studies document and analyze the day-to-day, traditional and non-traditional work of these women. From Kenya to Canada, from the isolated remote refugee camps to the hustle and bustle of cosmopolitan cities, from hauling water for daily subsistence, to providing health care to strangers for pay, these studies explore how refugee and immigrant women do their work and how they manage their daily lives.

As Jennifer Hydman's article on the daily work of Somali refugee women in the Kenyan camps of Ifo, Hagadera,

\section{Contents}

Introduction: Refugee and Immigrant Women as Workers

Guida Man

Shedding Their Refugee Skin: Constructions of Women Refugees and

International Aid Regimes Maryanna Schmuki

Representing Refugee Women: Gender and Work in

Three Kenyan Camps Jennifer Hyndman

Refugee Women in London: The Experiences of Somali Women Rosemary Sales and Jeanne Gregory.

Migration and the Transformation of Work Processes:

Voices of Chinese Immigrant Women in Canada Guida Man

Speaking with Migrant Women Health Care Aides:

On Marketing and Making Sense of Caregiving in Canada

Gail McCabe

Human Rightw: Setting the Stage for Protecting Refugee Women Maryanna Schmuki

Canadian Truth Commission Attempts to Overcome Guatemalan Refugees' Fear and Cynicism Judith Pyke. 
Centre for Refugee Studies Suite 322, York Lanes York University 4700 Keel Street, Toronto Ontario, Canada M3J 1 P3 Phone: (416) 36-5663 Fax. (416) 736-5837 Email: refuge@yorku.ca

Vol. 17 - No.1

February 1998

Editor

OIAELLANPImiR Guest

Editor GmDAMAN

Managing Editor

MAREKSWINDER

Refugeis dedicated to the encouragement of assistance to ref",geesby providing a forum for sharing information and opinion on Canadian and international issues pertaining to refugees. Refuge was founded in 1981.

It is published six times a year by the Centre for Refugee Studies, York University, Canada. Refuge is a nonprofit, indep ndeQ.t periodical supported by private donations and supported by private donations and
by subscriptions. It is a forum for by subscriptions. It is a forum for do notnec:essari1y reflect those ofits funders or staf£.

All material in Refuge may be reproduced withoutpermission unless copyrighted or otherwise indicated. Credit should be given to the author or source, if named, and Refuge. Submissions on related issues are welcome for publication consideration.

Current subscription rates for one year (six issues) are: Canada Cdn.\$50; all other countries u.s. $\$ 60$. (Cheques must be drawn on a Canadian or a U.S. bank.) Current volume single issues are available at $\$ 10$ per copy.

Please enclose your purchase order or payment.

ISSN0229:.s113 and Dagahaley illustrates, refugee women are not merely "vulnerable," helples victims of circumstance, passively accepting their fate. Hydman de construct this stereotypical notion by demonstrating that these women are active participant who employ various survival strategies and indigenous skills in their daily struggles, and who engage in informal cash economy to make ends meet.

For those refugee women who have higher education and professiona qualifications, they have always been able to combine work and family in their hom country due to the support of the extended family. This is confirmed by Rosemary Sales and Jeanne Gregory's study on the Somali refugee women in London. However, these highly educated Somali women professionals were unable to fin permanent employment in Britain despit an urgent need for Somali speakers in teaching, medicine and social work. This is so because Somali qualifications are not recognized in Britain, and few refuge women have the resources to undertak thenecessary training to allow them to work in Britain. Refugee women therefore face multiple barriers to employment due to their uncertain legal status, and the racialized and gendered structures of the labour market.

The employment barriers encountered by the Somali refugee women are also experienced by the Chinese immigran women in Canada as revealed in Guida Man's study. Man demonstrates that institutionalized discrminatory processes in the requirement of "Canadian experience, and the inadequacy of an accredition system to calibrate immigrant's qualifications make it diffi

cult for the Chinese immigrant women to obtain employment which commensurat with their qualifications and experience. Consequently, these women experienced underemployment and unemployment. The differences in the social organization of Canadian society vis-a.-vis their hom country also makes life increasingly difficult for these women, intensifying their daily workload.
Despite racism, class discrimination, and gender oppression, McCabe's investigation of migrant women health care aides in Canada found their care giving practice to be an aspect of an ethics of care that allows for moments of empowerment and resistance to an oppressive social context. McCabe argues that the Canadian market for care has been shaped largely by discourses that devalue women's work and commodify migrant women caregivers.

Departing from the theme on refugee and immigrant women as workers, this issue of Refuge also includes two provocative papers by Maryanna Schmuki. Her first paper opens the issue by interrogating the fundamental concern of how refugee women is constructed. In particular, she poses the questions: How do he know ledges created by the West about refugee women affect the process by which woman becomes a refugee? How does this knowledge affect the process and likelihood that the refugee will shed the abel "refugee"? How do women refugees become "normal" again and how do the groups intending to aid refugees mitigate this process? Are the voices of women refugees incorporated into the knowledge production process? In answering these questions, Schmuki explores how the development and humanitarian assistance establishment as a construction site produces a distinct discourse on refugee women. She contends that the knowledge produced creates an image

of the women refugee that may be intended to benefit not only the refugee herself, but also the regimes and individuals that make up the international system of emergency relief and assist

ance. She suggests that for refugee women to be able to shed their refugee skin, a delicate balance must be struck between the power inherent in the international aid community and the liberatory effects of the new found category of refugee women.

This issue of Refuge concludes with Schmukis' second paper which explores the development of women refugees as a category within human rights discourse. In her final paper, Schmuki reiterates her concern that given the 
western cultural values, western epistemology, and western institutional form predominant in the contemporary aid arena, how do human rights instruments and images help or hinder the process of women refugees returning to normalcy, i.e., does the construction of refugee women reflect the voices of women refugees? And how would refugee women be able to shed their refugee skin? These are significant considerations that we need to keep addressing and renegotiating. In order to adequately respond to these questions, I suggest we continue our dialogue with academics, practitioners, NGOs, grassroot organizers etc. working on issues concerning refugee and immigrant women in future issues of Refuge.

GuidaMan, Ph.D., teaches at Ryerson Polytechnic University, Toronto, and is a visiting research associate at the University of Toronto/York University Joint Centre for Asia Pacific Studies, York University, and an affiliate of the Centre of Excellence for Research on Immigration and Settlement, York University, Toronto, Canada.

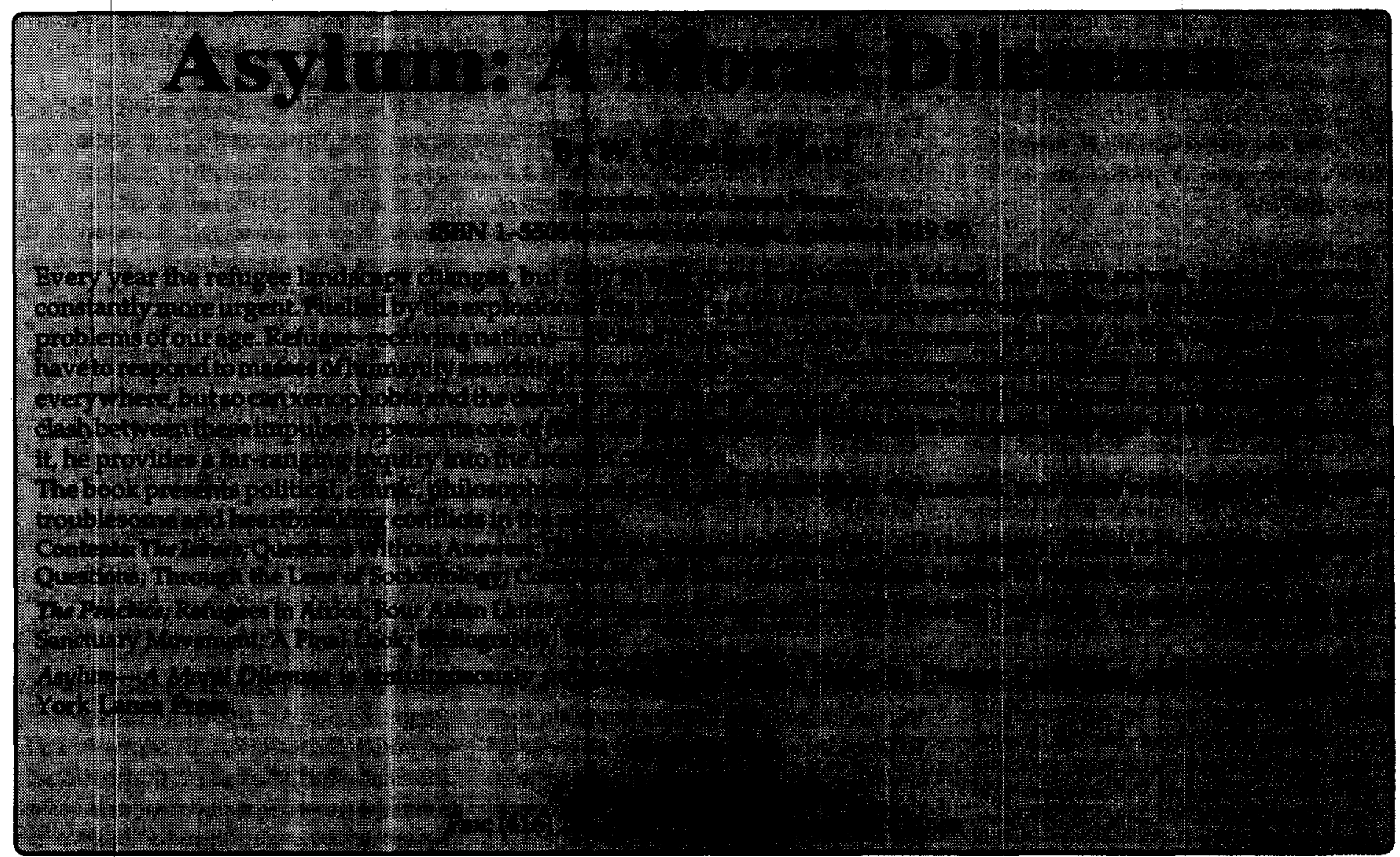

Refuge, Vol. 17,No. 1 (February 1998) 